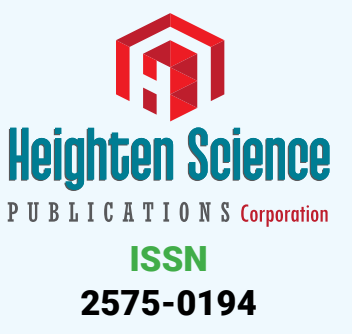

*Address for Correspondence: Mohammad Raies UI Haq, Assistant Professor, Department of Biochemistry \& Clinical Biochemistry, Sri Pratap College, Cluster University of Srinagar, Srinagar, J\&K, India, Email: raies_ulhaq@yahoo.com

Submitted: 15 June 2019

Approved: 26 June 2019

Published: 27 June 2019

Copyright: @ 2019 Ul Haq MR, et al. This is an open access article distributed under the Creative Commons Attribution License, which permits unrestricted use, distribution, and reproduction in any medium, provided the original work is properly cited

Keywords: $\beta$-casein; A1 $\beta$-casein; A2 $\beta$-casein; Type 1 diabetes

Check for updates
Review Article

\section{Possible links between consumption of A1 "like" milk And Type 1 Diabetes (T1D)}

\author{
Mohammad Raies UI Haq ${ }^{1 *}$, Asima $\mathrm{H}^{2}$ and Aarif $\mathrm{B}^{3}$ \\ ${ }^{1}$ Assistant Professor, Department of Biochemistry \& Clinical Biochemistry, Sri Pratap College, \\ Cluster University of Srinagar, Srinagar, J\&K, India \\ ${ }^{2}$ Lecturer, Department of Biochemistry \& Clinical Biochemistry, Sri Pratap College, Cluster \\ University of Srinagar, Srinagar, J\&K, India \\ ${ }^{3}$ National Post-Doctoral Fellow (NPDF), IIIM Srinagar, Srinagar, J\&K, India
}

\section{Abstract}

During the last three decades, there has been an interesting debate on the intake of A1 'like" milk and incidence of type 1 diabetes (T1D) in genetically predisposed individuals. The epidemiological, ecological and case-control studies have concrete pieces of evidences in favor of the hypothesis that is further supported by animal trials in mice and rat and in vitro trials on cell lines. But on the other hand, European Food Safety Authority reported that there isn't sufficient data to draw a final recommendation at this stage in terms of contradictory results, lack of cause-effect relationship and being a mere suggestive evidence [1]. However, the report itself states that these studies are strong enough to formulate a concrete hypothesis and further research is needed to confirm the same. Keeping in view the published data in favor of the hypothesis and the counter-arguments, it is suggested that further research with well-designed animal and in vitro trials with intact proteins and peptides is needed to fully confirm the hypothesis. Until the issue is fully resolved, it's the personal choice of the individuals at risk to T1D (genetically predisposed) to either remove A1 "like" or increase the A2 "like" milk from their diet.

\section{Introduction}

Type 1 diabetes (T1D) is basically regarded as an autoimmune disorder. This results when there is destruction in extremely significant pancreatic cells known as $\beta$-cells. This mostly occurs in individuals who are genetically predisposed to various environment factors most importantly from nutritive or dietary perspective $[2,3]$. The environmental has a considerable role to play in this disorder either through autoimmune responses or at the cellular levels involving the cell cycle through various check points $[4,5]$. Those external environmental stimulants include vaccines given in the childhood and/or viral infections. However, to the best of our knowledge, among one of the most significant potential candidates of diet includes cow milk proteins. Quite evidently, the most significant food of infants is milk, and since the subjects that lack breast feeding the cow milk proteins become a dominant alternative of their diet. It has been, therefore, observed the cow milk proteins to play an important role in the manifestations of T1D in those subjects who are genetically predisposed to T1D [6-8].

\section{Evidences in favour of a1/a2 milk hypothesis}

Historically, milk from dairy cows is used as a nutritional element solely for infants and partly for adults in most of the countries globally. The protein fraction of the milk has gained paramount reputation because of the nutritional and other functional attributes. However, more recently, deeper research with prevailing epidemiological data

How to cite this article: Mohammad Raies UI Haq, Asima H, Aarif B. Possible links between consumption of A1 "like" milk and Type 1 Diabetes (T1D). Arch Food Nutr Sci. 2019; 3: 010-016.

https://doi.org/10.29328/journal.afns.1001018 
and few mechanistically generated case cade mechanisms has correlated consumption of cow A1 milk protein with incidence of T1D in genetically predisposed individuals. This correlation has been established through epidemiological and ecological data, supported by case-control studies and further validated by in vivo (animal) and in vitro (cell lines) investigations. However, to the more surprise, these studies haven't been performed with the intact proteins alone but with the purified and/or commercially synthesized peptides.

In a similar type of study, the beneficial effects of breastfeeding over cow milk consumption were revealed by Scott in 1990. Nevertheless, to the more exactness, these findings couldn't explain causality [9]. Specifically, giving more emphasis to the protein family in milk, different variants of $\beta$-casein were compared in a study performed by Elliot and coworkers in 1999. These studies are based on epidemiological data and established a correlation between national annual cow milk protein consumption and incidence of T1D in different countries. The data generated by Elliot et al. (1999), kept an accurate regard of the cow breed composition and different genetic variants of $\beta$-casein. These two factors are the dominant functionalities in these types of studies. These findings were related to children below 14 year age and the 10 countries under study were USA, Canada, Germany, New Zealand, Sweden, Australia, Denmark, Finland, Iceland and Norway. The research group couldn't establish any correlation between total protein consumption and incidence of T1D incidence $(r=0.402)$, however, to a surprise, an association was developed between A1 milk intake and incidence of T1D $(r=0.726)$. These correlations were further strengthen when consumption of A1 "like" $\beta$-casein $(\mathrm{A} 1+\mathrm{B})$ was compared with incidence of T1D $(r=0.982)$. Furthermore, in one of these countries i.e., Iceland, where cows are predominantly A2, low numbers of cases of diabetes were observed. This lead to the conclusion that some unique element in the composition of A1 "like" $\beta$-casein might play a significant role incidence of T1D $[10,11]$. Later various investigation involving biochemical techniques revealed that a unique peptide sequence of 7 amino acids in A1 "like" $\beta$-casein variants is released through in vivo digestion or simulated gastrointestinal digestion (SGID). In conclusion, it was hypothesized that BCM-7 is released from only A1 "like" variants of $\beta$-casein and this peptide was ultimately considered as a hypothetical risk factor for incidence of T1D disease. The data generated through other studies [11,12] supported the earlier data of Elliot et al. (1999), where incidence of the T1D was observed significantly high in the regions where cows produced higher A1 "like" milk and consumption of this type of milk was also higher in humans. Thorsdottir et al. (2000), observed the data of Iceland and Scandinavia on milk protein polymorphism of $\beta$-casein protein. The findings from Iceland and Scandinavian countries observed a lower frequency of A1 and B $\beta$-casein varaints in Icelandic cow milk in comparison with Scandinavian countries. It was, therefore, reported that consumption of cow milk in infancy isn't correlated to incidence of T1D in Iceland. Therefore, the lower frequency of A1 "like" $\beta$-casein variants (A1 and B) in cow milk may explain a lower incidence of T1DM in these countries compared to Scandinavia. Similar reports were generated by McLachlan (2001) in children who were aged below 15 across 16 countries. A strong correlation $(r=$ 0.75) was established between incidence of T1D in children and consumption of A1 "like" $\beta$-casein [13]. These findings were further confirmed by Laugesen and Elliott in 2003 , with the same relationship in children aged below 14 year old between intake of A1 "like" $\beta$-casein and T1D across 19 countries. However, correlations were nonsignificant for the consumption of A2 variant of $\beta$-casein [14].

An early animal study examining the possibility of a relationship between milk protein consumption and diabetes was conducted by Elliot and Martin (1984). This study involved feeding BB rats with milk protein or an amino acid diet. Elliott and Martin concluded that cows' milk may contain a diabetogenic agent [15]. A further study by Elliott conducted in 1992, showed that rather than all milk being causative of Type 1 diabetes, 
it was possible that there was a link between digested casein, and more specifically a hexapeptide peptide derived from digested $\beta$-casein protein, and Type 1 diabetes. The implication of a bioactive protein fragment generated by the digestion of $\beta$-casein A1 was then reported in 1995 when, in an article title referring to $\beta$-casein variants as 'Jeckyl \& Hyde', it was further noted that this peptide bound macrophages and had known immunological activity [16]. In a similar animal trial, performed by Elliot and Hill in 1997 in mice (NOD) apparently clear-cut effects of A1 $\beta$-casein promoting diabetes and A2 providing protection was demonstrated. Another blinded international multicenter animal trail in two rodent models (NOD mice and BB rats) was performed in New Zealand (NZ), United Kingdom (UK) and Canada to analyse the effect of the effect of A1 and A2 $\beta$-casein variants on incidence of spontaneous T1D. NZ site was confounded by an infection and couldn't reach to a final conclusion. However, A1 $\beta$-casein was slightly more diabetogenic in the Canadian trial, but UK mice on A2 $\beta$-casein still developed diabetes. Overall, A1 \& A2 diets were found to be protective compared to control diets and varied little in diabetes-promoting capacity [17]. However, in these studies, the investigators were blinded which was apparently not the case in previous trials. Control diet composition was not revealed which is very important for an animal trial to furnish a final conclusion. Most of the studies use wheat as one of the components of basal diet, opioid peptides such as gluteomorphins, may be released from the wheat gluten that resembles $\beta$-casomorphins of milk. Therefore, may yield wrong information. More recently, a researcher group from china also found controversial reports on animal models. BCM-7 was observed to be has protective against hyperglycemia and free radical-mediated oxidative stress in streptozotocin-induced diabetic rats [18,19]. However, in their study, commercially synthesized BCM-7 was used; the more important native A1/A2 $\beta$-casein variants were not considered which the main objective of the present study. Also in this study, diabetes was induced with a chemical (streptozotocin), the main models of diabetes like NOD mice were not utilized. In conclusion, in animals, either A1 milk protein has found a clear correlation with T1D incidence through antibody profile or controversial reports are available through antioxidant status or antibody response. Therefore, proper animal models with perfect experimental design and diet composition are needed to evaluate the correlation of intact A1/A2 $\beta$-casein variants with incidence of the T1D.

More generally, a raised antibody profile against $\beta$-casein cow milk protein was observed in case-control studies, however, there was no distinction of $\beta$-casein protein polymorphism [20]. These studies gained more importance as distinction in antibody response was reported between A1 and A2 $\beta$-casein in subjects with T1D ( $n=287)$, their siblings $(n=386)$, their parents $(n=477)$ and healthy controls $(n=107)$. The findings showed a higher antibodies response against A1 $\beta$-casein in T1D patients and their siblings. Analysis of immune response to A1 $\beta$-casein, $\alpha$-casein, $\beta$-lactoglobin and Bovine serum albumin depicted an increased response against the $\beta$-casein. However, a substantial overlap with controls and an increase in antibody profile to other antigens lead to the conclusion of whether this evidence of immune activity is linked to the etiology of T1D or is a consequence of the disease process [21]. Moreover, a sensitization of T-cells against this milk protein was observed in T1D and a possibility of cross reaction was perceived with insulin-secreting cells in the pancreas [22,23]. However, these studies couldn't establish a cause-effect relationship. The longitudinal studies and/or feeding trials in humans demonstrating the roles of A1 and A2 $\beta$-casein in the etiology of T1D are scantly. Nevertheless, these studies are quite possible (especially within genetically at-risk infants) and therefore, would contribute substantially to such a significant substantiation.

\section{Possible mechanism}

Reports including epidemiological, ecological and case-controls provide a correlation between consumption of A1 cow milk and incidence of T1D. Animal studies 
in mice and rat and in vitro studies on cell lines further strengthen these observations. The biochemical mechanism revealing the structure of A1/A2 $\beta$-casein and possibility of release of BCM-7 from only $\mathrm{A} 1 \beta$-casein and the role of this peptide in the incidence of this disease in genetically predisposed individuals further support this hypothesis. The pharmacological properties revealing the opioid activity and binding affinity of BCM-7 further add in the development of this hypothesis. The immunological response observed through increased levels of antibodies against the $A 1 \beta$-casein in well-designed animal trials in NOD mice and BB rats may demonstrate the role of this variant of $\beta$-casein and incidence of T1D. BCM-7 released from only A1 "like" $\beta$-casein resembles morphine in structure and therefore, has opioid characteristics. Moreover, it has also been shown to inhibit human intestinal lymphocyte proliferation in vitro. Therefore, there is a possibility that such an immune suppressant influences the development of gut-associated immune tolerance, or suppresses defense mechanisms towards enteroviruses $[14,24]$. Also, in our laboratory, we observed gut inflammatory response of $\mathrm{A} 1 \beta$-casein and $\mathrm{BCM}-7$ that may create leaky gut $[25,26]$. All these immunological as well as pharmacological factors may substantially be implicated in the etiology of T1D. Mechanistically, the concept of 'cross-reactivity' between the peptides derived from cows' milk and amino acid sequences of pancreatic $\beta$-cell transporters like GLUT2 is appealing and has been proposed by several investigators [27]. The hypothesis that the exposure in infancy to A1 $\beta$-casein from cows' milk is etiologically associated with the development of T1D in genetically susceptible individuals is a fascinating one. Exactly how A1 $\beta$-casein affects the immune systems has not been determined. Certainly antibody response against A1 $\beta$-casein has been identified in people with T1D but these are seen in cross-sectional studies and need further investigations with deeper research. Also, sources of bias that could account for these high correlations are not apparent, and the ecological evidence demands more research. The other human observations are all case-control studies of immune responsiveness and these are somewhat supportive of the A1/A2 hypothesis. However, a very valid alternative explanation for the observed immune reactivity to $\beta$-casein is that it is a consequence of the disease process rather than a cause of it. The immediate and undisputable implication is that more research is urgently needed to investigate the A1/A2 hypothesis. Animal feeding trials on A1/A2 $\beta$-casein and determination of biochemical, immunological and physiological parameters are to be addressed with more sophisticated techniques like ELISA, flow cytometry, western blots, histology and gut microbiome analysis. A proper mechanism can be established from the reliable data generated from animal feeding trials followed by human clinical trials to show cause-effect relationship. If undesirable role of $\beta$-casein is established with T1D in animal and human studies, then we have to make specific recommendations to the public about actions to take (in relation to milk exposure) to prevent T1D and make policy-based decisions about reducing the exposure of infants to A1 milk.

\section{Arguments against the a1/a2 milk hypothesis}

The effect of consumption of A1/A2 "like" milk and an establishment of a hypothesis of incidence of T1D in genetically predisposed individuals has been subject of controversy. Although the diabetogenic effect of A1 milk has been observed in ecological, epidemiological and case-control studies. This effect has further been supported by in vivo trials in animal models including mice and/rat through assessment of antibody responses and other immunological parameters. Nevertheless, on the other hand, in 2009 European Food Safety Authority (EFSA) while assessing the hypothesis through clinical data on human health, reported that there isn't sufficient data to correlate consumption of A1 milk and incidence of T1D [1]. The report highlights that animal trials performed present some contradictory results, ecological studies couldn't establish cause-effect relationship fully. It is also reported that the correlation of consumption of A1 milk and T1D is only suggestive evidence. The issue highlighted is that the national A1 milk consumption shouldn't be the same as infant formulas (in which whey potion 
has been increased and casein protein decreased). In some countries like Switzerland, the T1D has increased three-fold since 1990 without a change in milk protein consumption [28]. However, the report itself reads that these studies are strong enough to formulate a concrete hypothesis and further research is needed to confirm the same. However, to the best of our knowledge, keeping in view the published data in favour of the hypothesis including ecological, epidemiological, case-control studies, in vivo (animal) and in vitro trials can't be ignored. Therefore in conclusion the present status of the hypothesis is on the stage where further research with well-designed animal and cell lines trials on intact proteins and peptides is needed to fully confirm the results.

\section{Conclusion}

The possible links between consumption of A1 "like" milk and incidence of T1D in genetically susceptible individuals is potentially very important for consumer health. The hypothesis is based on the data generated from ecological, epidemiological, casecontrol studies. The animal feeding trials in mice and rat and in vitro trials on cell lines with purified proteins or commercialized synthesized peptides (BCM-7). There are various mechanisms supporting this hypothesis starting from variant specific release through pharmacological opioid activity to immunological activities. Although the hypothesis is possibly strong, however, the presentation of controversial data and cross-sectional studies deserve further investigations with deeper research.

To the best of our knowledge, keeping in view the published data in favor of the hypothesis, including ecological, epidemiological, case-control studies, in vivo (animal) and in vitro trials need considerable attention. On the other hand, the statements presented by EFSA report (2009) can't also be ignored. Therefore, in conclusion the present status of the hypothesis on the stage where further research with welldesigned animal and cell lines trials on intact proteins and peptides is needed to fully affirm the results. Until proven correct with more research at cellular and molecular level, it the personal choice of the individuals at risk to T1D (genetically predisposed) either to remove this variant of $\beta$-casein from their diet or increase the A2 $\beta$-casein in their diet.

\section{Future perspectives}

In our opinion the current status of the issue regarding the intake of A1 "milk" in the diet puts forward following necessary actions:

More funding is required for clinical trials in humans and animal feeding trials followed by in vitro trials on cell lines. These efforts will surely demonstrate causeeffect relationship in addition to unravelling the mechanistic pathways at biochemical, immunological and physiological levels.

The consumers should be made aware through awareness programmes regarding the current status of the hypothesis. However, at the same time the evidences and uncertainties of this cause-effect relationship must be discussed with comprehensive literature including controversial data. Moreover, considerations of the assertions announced in the public about health benefits of A2 milk should be properly checked and making sure that they fall within food safety regulations.

Only when the issue is resolved and the cause-effect relationship is proved at all stages including ecological, cellular and molecular levels in future, then Governments should come up with polices and recommend people who are predisposed to diabetes to provide full considerations regarding the issue.

After proving it correct in future, the Governments will have an option to remove this variant from diet and/or alternatively shifting the herds of bovines and buffalos to A2 milk through proper genetic breeding polices. 
Overall, after the issue is resolved through comprehensive research trials and other experimentation, it will be more intriguing and potentially important for consumer health and industrial applications to formulate guidelines for intake of A1/A2 "type" milk to correlate it fully with incidence of type 1 diabetes in genetically predisposed individuals.

\section{References}

1. EFSA, European Food Safety Authority. Review of the potential health impact of $\beta$-casomorphins and related peptides. Scientific Report n. 231. 2009; 1-107. Ref.: http://bit.ly/2X7wxL3

2. Atkinson MA, Eisenbarth GS. Type 1 diabetes: New perspectives on disease pathogenesis and treatment. Lancet. 2001; 358: 221-229. Ref.: http://bit.ly/2Ygd7A9

3. Bluestone JA, Herold K, Eisenbarth G. Genetics, pathogenesis and clinical interventions in type 1 diabetes. Nature. 2010; 464: 1293-1300. Ref.: http://bit.ly/2LqbFrd

4. Todd JA. A protective role of the environment in the development of type 1 diabetes? Diabetic Medicine.1991; 8: 906-910. Ref.: http://bit.ly/2IScqaV

5. Todd JA. Etiology of type 1 diabetes. Immunity. 2010; 32: 457-467. Ref.: http://bit.ly/2XbnqJo

6. Chia JSJ, McRae JL, Kukuljan S, Woodford K, Elliott RB, et al. A1 beta-casein milk protein and other environmental pre-disposing factors for type 1 diabetes. Nutrition \& Diabetes. 2017; 15; 7:e274. Ref.: http://bit.ly/2LmKPAb

7. Knip M, Veijola R, Virtanen SM, Hyöty $\mathrm{H}$, Vaarala $\mathrm{O}$, et al. Environmental triggers and determinants of type 1 diabetes. Diabetes. 2005; 54: S125-S136. Ref.: http://bit.ly/2xf9ajp

8. Coppieters KT, von Herrath MG. Histopathology of type 1 diabetes: old paradigms and new insights. Rev Diabet Stud. 2009; 6: 85-96. Ref.: http://bit.ly/2FxYr7V

9. Scott FW. Cow milk and insulin-dependent diabetes mellitus: Is there a relationship? Am J Clin Nutr. 1990; 51: 489-491. Ref.: http://bit.ly/2xbKjwP

10. Elliott RB, Harris DP, Hill JP, Bibby NJ, et al. Type I (insulin-dependent) diabetes mellitus and cow milk: casein variant consumption. Diabetologia. 1999; 42; 292-296. Ref.: http://bit.ly/2RGI1iz

11. Thorsdottir I, Birgisdottir BE, Johannsdottir IM, Harris DP, Hill J, et al. Different $\beta$-casein fractions in Icelandic versus Scandinavian cow's milk may influence diabetogenicity of cow's milk in infancy and explain low incidence of insulin-dependent diabetes mellitus in Iceland. Pediatrics. 2000; 106: 719724. Ref.: http://bit.ly/2X12Cz7

12. Birgisdottir BE, Hill JP, Harris DP, Thorsdottir I. Variation in consumption of cow milk proteins and lower incidence of Type 1 diabetes in Iceland vs the other 4 Nordic countries. Diabetes Nutr Metab. 2002; 15: 240-245. Ref.: http://bit.ly/2XcMQWX

13. McLachlan CNS. Breeding and milking cows for milk free of $\beta$-casein A1. A2 Corporation, US 7863002B2. 2001. Ref.: http://bit.ly/2X9VXrx

14. Laugesen $M$, Elliott R. Ischaemic heart disease, type 1 diabetes, and cow milk $A 1 B$-casein. $N Z$ Med J. 2003; 116: 121-132. Ref.: http://bit.ly/2RBxpSd

15. Elliot RT, Martin JM. Dietary protein: A trigger of insulin dependent diabetes in BB rat. Diabetologia 1984; 26: 297-299. Ref.: http://bit.ly/2XuSGCo

16. Elliot RB, Hill RJ. Method of selecting non-diabetogenic milk or milk products and milk or milk products so selected. A2 Corporation. 1995; CA2204245: PCT/NZ1995/000114.

17. Elliott RB, Wasmuth $\mathrm{H}$, Hill J. Immunosuppressing effects of cow milk $\beta$-casomorphins in prediabetic mice and humans. $16^{\text {th }}$ IDF Congress, Helsinki. 1997.

18. Yin $\mathrm{H}$, Miao J, Zhang Y. Protective effect of $\beta$-casomorphin-7 on type 1 diabetes rats induced with streptozotocin. Peptides. 2010; 31: 1725-1729. Ref.: http://bit.ly/2Xe6YrB

19. Yin $\mathrm{H}$, Miao J, Ma C, Sun G, Zhang Y. $\beta$-casomorphin-7 cause decreasing in oxidative stress and inhibiting NF-KB-iNOS-NO signal pathway in pancreas of diabetes rats. J Food Sci. 2012; 77: C278282. Ref.: http://bit.ly/2IP5CuK

20. Cavallo MG, Monetini L, Walker B, Thorpe R, Pozzilli P. Diabetes and cow's milk. Lancet. 1996; 348: 1655.

21. Padberg S, Schumm-Draeger PM. "Significance of $A 1$ and $A 2$ antibodies against $\beta$-casein in insulin- 
dependent diabetes mellitus". Deutsche Medizinische Wochenschrift. 1999; 124: 1518-1521. Ref.: http://bit.ly/2LhpCYy

22. Monetini L, Barone F, Stefanini L, Petrone A, Walk T, et al. Establishment of $T$ cell lines to bovine $\beta$-casein and $\beta$-casein-derived epitopes in patients with type 1 diabetes. J Endocrinol. 2003; 176: 143-150. Ref.: http://bit.ly/2ZU6IL9

23. Banchuina N, Boonyasrisawata W, Vannasaengb S, DharakulaPa-thai T, Chaicharn Deerochanawongd $Y$, et al. Cell-mediated immune responses to GAD and $\beta$-casein in type 1 diabetes mellitus in Thailand. Diabetes Res Clin Pract. 2002; 55: 237-245. Ref.: http://bit.ly/2ZQUiUo

24. Elliott RB, Wasmuth $\mathrm{H}$, Hill J. Immunosuppressing effects of cow milk $\beta$-casomorphins in prediabetic mice and humans. $16^{\text {th }}$ IDF Congress, Helsinki. 1997.

25. UI Haq MR, Kapila R, Saliganti V. Consumption of $\beta$-casomorphins- $7 / 5$ induce inflammatory immune response in mice gut through Th2 pathway. J Functional Foods. 2014a; 8: 150-160. Ref.: http://bit.ly/2RDb1HX

26. UI Haq MR, Kapila R, Sharma R, Saliganti V, Kapila S. Comparative evaluation of cow $\beta$-casein variants (A1/A2) consumption on Th2-mediated inflammatory response in mouse gut. Eur J Nutr. 2014b; 53: 1039-1049. Ref.: http://bit.ly/2JcUkze

27. Harrison LC, Honeyman MC. Cow's milk and type 1 diabetes: The real debate is about mucosal immune function. Diabetes. 1999; 48: 1501-1507. Ref.: http://bit.ly/2NhiH43

28. Crawford RA, Boland MJ, Hill JP. Changes over time in the association between deaths due to ischaemic heart disease and some main food types. Australian Journal of Dairy Technology. 2003; 58: 183. Ref.: http://bit.ly/2X4ubri 